\title{
Agonist-Like or Antagonist-Like Treatment for Cocaine Dependence with Methadone for Heroin Dependence: Two Double-Blind Randomized Clinical Trials
}

\author{
John Grabowski*,', Howard Rhoades', Angela Stotts', Katherine Cowan', Charles Kopecky', \\ Anne Dougherty', F Gerard Moeller', Sohela Hassan' and Joy Schmitz' \\ 'Department of Psychiatry and Behavioral Sciences, School of Medicine, Substance Abuse-Mediation Development Research Center, University of \\ Texas-Health Science Center, Houston, Houston, TX, USA; ${ }^{2}$ Department of Internal Medicine, School of Medicine, University of Texas-Health \\ Science Center, Houston, Houston, TX, USA
}

\begin{abstract}
Concurrent abuse of cocaine and heroin is a common problem. Methadone is effective for opioid dependence. The question arises as to whether combining agonist-like or antagonist-like medication for cocaine with methadone for opioid dependence might be efficacious. Two parallel studies were conducted. One examined sustained release $d$-amphetamine and the other risperidone for cocaine dependence, each in combination with methadone. In total, 240 subjects (I20/study) were recruited, who were both cocaine and heroin dependent and not currently receiving medication. All provided consent. Both studies were carried out for 26 weeks, randomized, double-blind and placebo controlled. Study I compared sustained release d-amphetamine (escalating I5-30 or 30-60 mg) and placebo. Study II examined risperidone (2 or $4 \mathrm{mg}$ ) and placebo. All subjects underwent methadone induction and were stabilized at $1.1 \mathrm{mg} / \mathrm{kg}$. Subjects attended clinic twice/week, provided urine samples, obtained medication take-home doses for intervening days, and completed self-report measures. Each had one behavioral therapy session/week. In Study I, reduction in cocaine use was significant for the $30 / 60 \mathrm{mg}$ dose compared to the 15/30 mg and placebo. Opioid use was reduced in all groups with a trend toward greater reduction in the 30/ $60 \mathrm{mg}$ d-amphetamine group. In Study II, methadone reduced illicit opioid use but cocaine use did not change in the risperidone or placebo groups. There were no adverse medication interactions in either study. The results provide support for the agonist-like ( $d$ amphetamine) model in cocaine dependence treatment but not for antagonist-like (risperidone) treatment. They coincide with our previous reports of amphetamine or risperidone administered singly in cocaine-dependent individuals.

Neuropsychopharmacology (2004) 29, 969-98I, advance online publication, 24 March 2004; doi:I 0.I 038/sj.npp. I 300392
\end{abstract}

Keywords: cocaine/heroin pharmacotherapy; d-amphetamine; risperidone; dual dependence; cocaine abuse; heroin abuse; treatment

\section{INTRODUCTION}

A common and difficult clinical problem in the field of substance use disorders is concurrent cocaine and heroin dependence (Leri et al, 2003; Katz et al, 2002; Villano et al, 2002). Neither agonist-like (Use of agonist-like and antagonist-like is broader than a precise pharmacological definition. The goal, as with terms such as replacement and substitution, is to convey behavioral and physiological similarities but not identical underlying mechan-

\footnotetext{
*Correspondence: Dr J Grabowski, SARC Department of Psychiatry and Behavioral Sciences, University of Texas Health Science Center, Houston, 1300 Moursund, Houston, TX 77030, USA, Tel: + 1713 5002862 or 500 2797, Fax: + I 7135002849 ,

E-mail: john.grabowski@uth.tmc.edu

Received 28 March 2003; revised 05 December 2003; accepted 21 December 2003

Online publication: 31 December 2003 at http://www.acnp.org/ citations/Npp | 23 10303 | 33/default.pdf
}

isms.) nor antagonist-like medications have been demonstrated as being uniquely effective for treatment of cocaine dependence. Both forms of pharmacotherapy have been effectively used for heroin dependence. Methadone can effectively reduce heroin use even in the presence of persistent or increased cocaine use (Rhoades et al, 1998). Effects of methadone on concurrent cocaine use are equivocal with reports of both reductions and increases in use in methadone-maintained patients (Stine et al, 1991; Rhoades et al, 1998). The outcome may be dependent on the pattern of use of the two drugs, stable methadone dose, or both.

Administration of methadone for heroin dependence combined with agonist or antagonist medications for cocaine dependence may be essential to diminish cocaine use while achieving the usual reductions in opioid use. At the same time, interactions between methadone and a candidate cocaine treatment agent might facilitate or impair the action of one or both drugs. 
Agonists administered via a route with a slower onset than the abused drug have been effective for treatment of opioid and nicotine dependence. Rothman et al (2002) have argued in favor of several nonamphetamine 'appetite suppressants' as candidates for the treatment of stimulant dependence. However, among readily available medications, none other than the amphetamine analogs are particularly effective reinforcers as was demonstrated in animal selfadministration research (Griffiths et al, 1981). Therefore, some appetite suppressants (Rothman et al, 2002) may not represent an adequate combination of biological and behavioral stabilization and reinforcing effectiveness that is found with opioid agonists for opioid dependence. Still, there are advantages and disadvantages to the stabilization-reinforcing combination in agonist treatment (Platt et al, 2002).

d-Amphetamine overlaps several biological and behavioral actions of cocaine in and therefore might serve as effective pharmacotherapy. Charnaud and Griffiths (1998) reported positive results in a descriptive study of a clinical population receiving $\mathrm{d}$-amphetamine for intravenous amphetamine dependence, with effectiveness approximating that for methadone in their heroin-dependent population. Shearer et al $(1999,2001)$ and Klee et al (2001) have provided further evidence of the utility of prescribed $\mathrm{d}$-amphetamine as a replacement strategy for amphetamine abusers. Additionally, Shearer et al (2002) have made a cogent case for the advantages of substitution therapy. Grabowski et al (2001) reported reduced cocaine use with sustained release oral d-amphetamine compared to placebo in cocaine-dependent patients. Using an immediate release preparation, Shearer et al (2003) found trends but not a statistically significant effect in a cocaine-using population. Directly relevant preclinical results are those of Negus and co-workers (eg Negus and Mello, 2003a,b), who reported that $\mathrm{d}$-amphetamine pretreatment produced reductions in cocaine self-administration. Meisch (personal communication, 2003) has also demonstrated large reductions in rhesus monkeys self-administering cocaine orally. Both have found substantial suppression of cocaine selfadministration at doses approximating those used in the study reported here, and an earlier clinical trial (Grabowski et al, 2001).

Reports suggested that risperidone, by virtue of its antidopaminergic activity, might be efficacious as an antagonist-like treatment for cocaine dependence. For example, Roy et al (1998) reported decreased cocaine craving in withdrawn cocaine-dependent patients following risperidone treatment. However, Wachtel et al (2002) reported that risperidone did not reduce stimulant-like effects of methamphetamine, and suggested that D2 dopamine receptor antagonists will not block the positive subjective effects of cocaine. The literature on dopaminergic mechanisms and antagonism with respect to treatment is complex and equivocal (Platt et al, 2002; Mello and Negus, 1996). Risperidone has been found to be well tolerated in the treatment of other psychiatric disorders (GutierrezEsteinou and Grebb, 1997). However, while $8 \mathrm{mg}$ risperidone had undue side effects, 2 and $4 \mathrm{mg}$ risperidone administered in single diagnosis cocaine-using subjects produced no reduction in cocaine use (eg Grabowski et al, 2000a; Levin et al, 1999; Nunes, personal communication,
2002), although risperidone has been reported to diminish 'craving' (Newton et al, 2001).

The conceptual and pragmatic bases for antagonist treatment are sound. Diminution of opioid use in conjunction with naltrexone treatment provides the prototypic case. Practical disadvantages in antagonist treatment reside in relatively low patient acceptance and compliance despite efficacy. Still, early on, naltrexone was suggested to be useful in well-motivated patients or when external contingencies sustain compliance (Greenstein et al, 1981; Grabowski et al, 1979) and this perspective continues (Preston et al, 1999). Administering methadone for opioid dependence while administering an antagonist for cocaine dependence might enhance retention compared to that resulting from antagonist administration alone and reduce cocaine use.

Two parallel studies were implemented concurrently in dually dependent patients. These studies were directly comparable in procedures and had common features with the previously mentioned reports with $\mathrm{d}$-amphetamine and risperidone in single diagnosis patients. The principal difference between these studies and two earlier reports was duration, with the single diagnosis studies being 3 months and the dual diagnosis studies being 6 months. It was predicted that $\mathrm{d}$-amphetamine in Study $\mathrm{I}$ and risperidone in Study II would attenuate or eliminate cocaine use while methadone would reduce or eliminate opioid use. Both studies were reviewed and approved by the Committee for the Protection of Human Subjects, University of Texas, Health Science Center-Houston.

\section{METHODS}

General and specific methods for the two studies were identical. The principal design difference resided in the twostage dosing schema for Study I, which was directly comparable to the single diagnosis d-amphetamine report (Grabowski et al, 2001). Subjects were alternately assigned to the two studies described here and then randomly assigned to the respective treatment conditions.

\section{Study I: d-Amphetamine for Cocaine and Methadone for Opioid Dependence}

\section{Method.}

Subjects: Informed consent and intake evaluation were completed for 120 dual dependent subjects (cocaine + heroin), 18-50 years of age, in good medical health without other psychiatric diagnoses (except nicotine dependence), determined by the Structured Clinical Interview-DSM IV (SCID; First et al, 1995). The subjects were not previously receiving methadone and were not previously enrolled in ongoing Treatment Research Clinic studies and met the criteria for cocaine and heroin dependence. The primary additional inclusion criterion required a normal range of cardiac function as determined by 12 lead EKG, history, and physical exam. The EKGs were reviewed by a collaborating cardiologist (author AD) at intake and at two-week intervals throughout the study.

Design: All subjects received a stable methadone dose throughout the study following a 7-10-day run-up. Subjects 
Table I Design, Study I

\begin{tabular}{lllllll}
\hline Phases & Intake & Stabilization I & Phase I & Stabilization II & Phase II & Study end \\
\hline $\begin{array}{l}\text { Duration } \\
\text { Groups }\end{array}$ & 2 days & 10 days & 28 days & 7 days & 140 days & $7-10$ days d-amph 60 days methadone \\
$\begin{array}{l}\text { Placebo+methadone } \\
\text { No drug }\end{array}$ & Placebo+1.1 mg/kg & Placebo $+1.1 \mathrm{mg} / \mathrm{kg}$ & Placebo+1.1 mg/kg & Placebo+1.1 mg/kg & Dose reductions \\
d-Amphet+methadone & No drug & $15 \mathrm{mg}+1.1 \mathrm{mg} / \mathrm{kg}$ & $15 \mathrm{mg}+1.1 \mathrm{mg} / \mathrm{kg}$ & $30 \mathrm{mg}+1.1 \mathrm{mg} / \mathrm{kg}$ & $30 \mathrm{mg}+1.1 \mathrm{mg} / \mathrm{kg}$ & Dose reductions \\
d-Amphet+methadone & No drug & $30 \mathrm{mg}+1.1 \mathrm{mg} / \mathrm{kg}$ & $30 \mathrm{mg}+1.1 \mathrm{mg} / \mathrm{kg}$ & $60 \mathrm{mg}+1.1 \mathrm{mg} / \mathrm{kg}$ & $60 \mathrm{mg}+1.1 \mathrm{mg} / \mathrm{kg}$ & Dose reductions \\
\hline
\end{tabular}

were randomly assigned to placebo or one of two active damphetamine doses in this double-blind trial (Table 1). The incremental dosing design included run-up, 4 weeks at a lower dose, a dose-doubling week, with the higher dose in place for the remaining 20 weeks of study. This approach was determined in consultation with a NIDA expert panel (1996-1997) based on concerns of potential tolerance or sensitization.

Psychosocial therapy: Manual-driven cognitive behavioral/ relapse prevention psychosocial therapy developed at this site and used in previous studies (Grabowski et al, 2000a, b, 2001) was provided $1 \mathrm{~h}$ each week by master's-level therapists. Sessions were audio taped and $1 / 3$ were reviewed by a clinical psychologist co-investigator (AS) to maintain treatment fidelity. Subjects were discouraged from attending other therapy or self-help groups.

Medication: The d-amphetamine sulfate-sustained release (Dexedrine Spansule Capsules, GlaxoSmithKline) regimen was twice daily, one capsule within $2 \mathrm{~h}$ of awakening, and one $6 \mathrm{~h}$ later. Capsules containing placebo or medication were identical and included a total daily dose of $100 \mathrm{mg}$ of riboflavin. The proprietary capsules were put in larger capsules packed with riboflavin by the clinic pharmacist who also applied the labels with clinic contact and safety information as well as group coding. Medication Event Monitoring System (MEMS: Aardex, Switzerland) bottles were used with two capsules in each bottle/day throughout the study for take-home days. The morning or afternoon dose, depending on appointment time, occurred under nurse observation in the clinic on the two visit days each week (eg Monday-Thursday). Subjects received the lower dose of d-amphetamine for 4 weeks ( 15 or $30 \mathrm{mg}$ ). The dose was doubled (to 30 or $60 \mathrm{mg}$ ) in week 5, and then maintained for 20 subsequent study weeks. d-Amphetamine dosing was decreased and eliminated in a 7-10-day period at study completion.

The methadone induction for all subjects continued to a final dose of $1.1 \mathrm{mg} / \mathrm{kg}$ in the first 7-10 days of stabilization. Doses on the twice-weekly clinic visit days were ingested on site and observed. Each off-site dose was packaged in a separate dispensing bottle to be consumed at the usual medicating time by the subject. At study end, subjects underwent a 2-month dose reduction protocol or were transferred to other clinics where methadone was available.

Nurses monitored medication supplies, return of unused doses, ingestion on visit days, and encouraged compliance.
Urine samples were obtained on visit days to monitor medication and riboflavin fluorescence.

Measures and data analysis: SCID, Addiction Severity Index (ASI-McLellan et al, 1992), Beck Depression Inventory (BDI, Beck et al, 1996), and Drug History along with standard physical examination and history, TB and HIV testing, urine screens, and an EKG were conducted at intake. A Side Effects Questionnaire (SEQ) and the BDI were administered weekly.

Urine sample collection was observed using a video recording system with tapes reviewed and erased daily by clinic nurses. Samples obtained at each visit from intake consent to study conclusion were also temperature checked and a rigorous chain of custody was maintained. Samples were screened for the full range of commonly abused and therapeutic drugs, including opiates, cocaine, marijuana, amphetamines, benzodiazepines, antipsychotics, antiepileptics, and mood stabilizers in the Analytical Neurochemistry Laboratory on site. Riboflavin was evaluated using a standardized fluorescence measurement/observation procedure. Breath alcohol levels were obtained at each visit using an AlcoSensor II. The use of MEMS bottles combined with urine screen drug metabolite, and riboflavin fluorescence measures permitted evaluation of compliance.

Descriptive and univariate statistics were calculated for intake demographic and patient characteristic data to check for any baseline group differences. Retention data were analyzed using a parametric survival analysis, and final group completion rates were compared using a $\chi^{2}$ test. Repeated measures data from this study were analyzed using SAS's Proc Mixed for unbalanced repeated measures data. This method uses all observed data and subjects are not deleted from the analysis unless they contribute no data.

\section{Results}

Subjects: Subjects were recruited to meet the criteria for cocaine and heroin dependence on intake interviews. In all, 120 subjects signed consent forms and were evaluated. No subject offered the opportunity for participation refused. In all, 26 of the subjects either did not meet inclusion criteria and were transferred or moved to other studies. A total of 94 subjects were given study medication (intent-to-treat sample). In all, 32 of the subjects discontinued the treatment during the d-amphetamine stabilization period. Out of the 62 who remained in the study (evaluable sample), four dropped out after the first month and another 24 dropped out during the dose doubling phase of the study. A total of 34 subjects completed the 6-month 
study. The mean baseline methadone dose for subjects in the three groups was $73 \mathrm{mg}$ based on the $1.1 \mathrm{mg} / \mathrm{kg}$ dosing strategy.

Sample characteristics: Of the 94 subjects (intent to treat sample), $33 \%$ were female, $10.6 \%$ black, $75.5 \%$ white, and $13.8 \%$ Hispanic. Unemployment was $59.6 \%$, average age was 36.7 (SD 7.3) years, and education was 12.3 (SD 2.4) years. Cocaine use at intake was crack or freebase $(46.8 \%)$, powder or snow (31.9\%), or 'speedball' (21.3\%). The frequency of use reported was 'less than once/month,' 4.3\%; 'less than once/week,' 9.6\%; 'once/week,' $13.8 \%$; 'several times/week,' 41.5\%; 'once/day,' 26.6\%; and 'greater than three times/day,' $4.3 \%$. There were no differences across groups on these measures. Nearly identical values and distributions were observed for the $n=62$ subjects in the evaluable sample.

Retention: Based on the intent-to-treat sample $(n=94)$, study completion rates for placebo, $15-30 \mathrm{mg}$, and $30-60 \mathrm{mg}$ groups were: $25.0,50.0$, and $39.3 \%$, respectively. The differences did not reach conventional levels of significance (likelihood ratio (LR) $\chi^{2}=4.48, \mathrm{df}=2, p=0.107, N=94$ ). A survival analysis, however, did indicate that the shapes of the retention curves differed at the trend level $\left(\chi^{2}=5.65\right.$, $\mathrm{df}=2, p=0.059, N=94)$. Examining the evaluable sample $(n=62)$ and following retention from the beginning of the 24-week study period, the study completion rates for the placebo, $15-30 \mathrm{mg}$, and $30-60 \mathrm{mg}$ groups were $50.0,56.6$, and $57.9 \%$, respectively. These differences were not statistically significant, nor were differences observed in the survival curves $(p>0.50)$ (Figure 1).

Compliance: d-Amphetamine positive urine screen proportions throughout the study phase were 3,61 , and $67 \%$ for the placebo, $15 / 30$, and $30 / 60 \mathrm{mg}$ dose groups, respectively, based on the evaluable sample $(n=62)$. After dose doubling, the compliance rate overall for the $60 \mathrm{mg}$ group was $75 \%$ in each month $3-6$. Compliance trended downward after dose doubling for the $30 \mathrm{mg}$ group and was in months 3-6 respectively, $61,59,53$, and $55 \%$. Compliance measured by riboflavin fluorescence (cutoff $<10$ ) was $0.77,0.78$, and 0.80 for the $0,15 / 30$, and $30 / 60 \mathrm{mg}$ dose groups, respectively.

Dropouts and side effects: Of the subjects, $2 \%$ gave medication side effects as reasons for dropping out. Differences in side effects frequency on the 33-item list collected each week were analyzed as a function of dose and time using Maximum Likelihood Repeated Measures. Few items varied when intake values were used as covariates. Side effects were grouped for weeks 1-4, for 2 months of dose doubling, weeks 5-12, and the remainder of the double dose period, weeks 13-24. There were differences across time (weeks 1-4, 5-12, and 13-24) after baseline was covaried. Several items decreased across time (all $p$ 's $<0.05$ ) including eating differently, more alert, constipated, more energy, and drowsy. Three items varied in an interactive manner: less anxious $(\mathrm{F}=2.58, \mathrm{df}=4,44, p=0.0501$, $n=62)$; happier $(\mathrm{F}=2.68, \mathrm{df}=4,46, p=0.0335, n=62)$; and dose too low $(\mathrm{F}=2.64, \mathrm{df}=4,46, p=0.046)$. In each of these three cases, the higher dose groups' ratings decreased over time while the lower dose and placebo groups' scores were essentially flat. The only item to vary by dose group alone was 'breathe faster sometimes' $(\mathrm{F}=3.79, \mathrm{df}=2,58$, $p=0.0284, n=62$ ), with individuals endorsing it more often as the dose level increased.

Cocaine use: Urine screens were considered presumptive for cocaine if benzoylecognine (BE) levels were $300 \mathrm{ng} / \mathrm{ml}$ or greater. There was no difference in result whether examined by a dichotomous positive/negative indicator or a creatinine-adjusted quantitative $\mathrm{BE}$ measure. The proportion urine screens positive at the initial intake screen for the intent-to-treat sample was $0.48,0.77$, and 0.64 for subjects randomized to the $0,15 / 30$, and $30 / 60 \mathrm{mg}$ groups, respectively. These differences were significant (Pearson $\chi^{2}=5.94$,

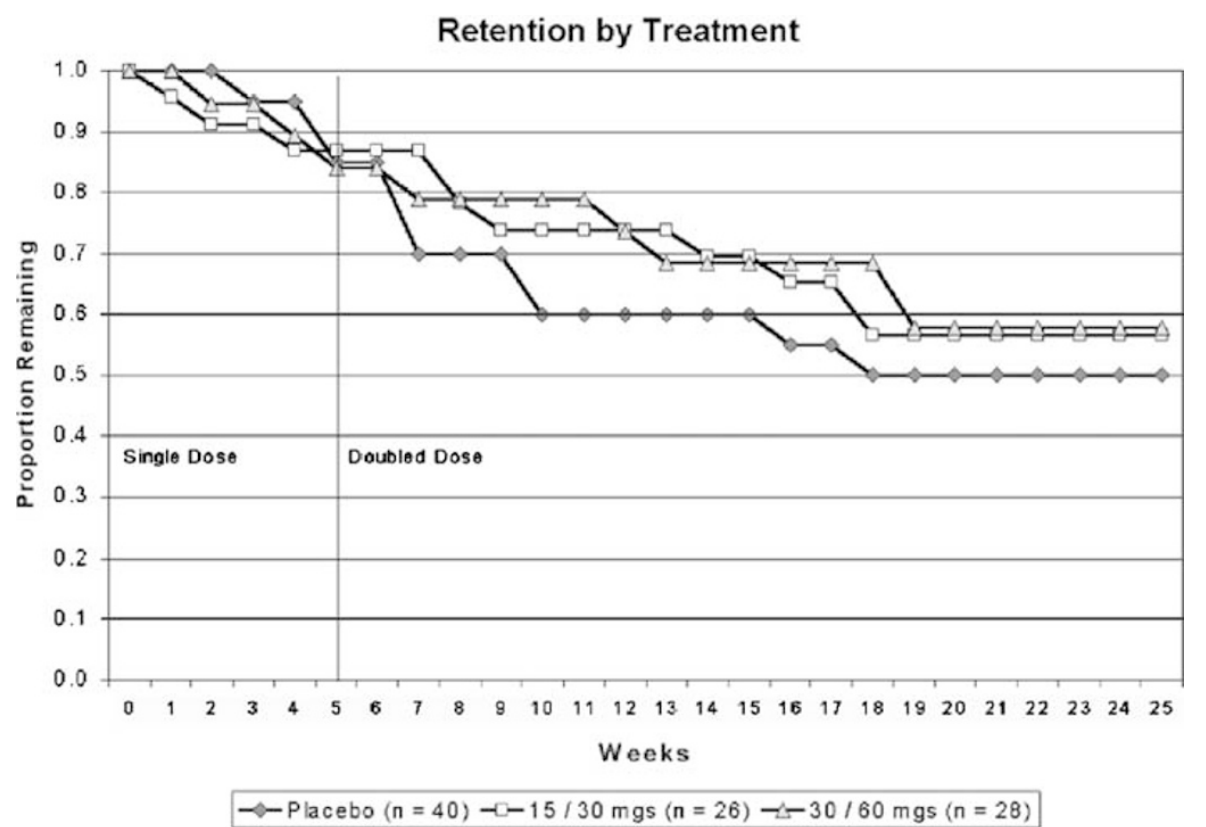

Figure I Retention for two active d-amphetamine + methadone and placebo + methadone groups (the vertical line indicates $d$-amphetamine dose doubling). 
$\mathrm{df}=2, p=0.05, n=94)$. For the evaluable sample, values of $0.65,0.78$, and 0.58 were observed for subjects randomized to the $0,15 / 30$, and $30 / 60 \mathrm{mg}$ groups, respectively $(p>0.35)$. Figure 2a (top) represents cocaine use across time by groups. The cocaine use by the $30-60 \mathrm{mg}$ group decreased after the first study month, corresponding to the onset of the dose doubling period. Analysis comparing the single to doubled dose phases (with intake cocaine urine screen as a covariate) indicated that the $30 / 60$ dose group significantly reduced cocaine use compared to the other groups, which maintained their cocaine use rates (Interaction $\mathrm{F}=4.34$, $\mathrm{df}=2,56, \quad p=0.0176$; Cohen's effect-size $f=0.394)$. As reported previously, intake urine screen $\mathrm{BE}$ is predictive of outcome $(\mathrm{F}=30.3 \mathrm{df}=1,58, p=<0.0001)$. Quantitative $B E$ data produced the same pattern with dose by time effects. Finally, a subsequent analysis of BE-positive urine screens, using Fisher's conservative 'least-significant difference' method, indicated that the $60 \mathrm{mg}$ per day group had fewer positive screens than either the $30 \mathrm{mg}$ or placebo groups at months 2, 3, and 4 (post hoc adjusted $p$-values of $0.058,0.061$, and 0.054 , respectively; Figure $2 \mathrm{a}$ ).

Illicit opioid use: Subjects did not differ in terms of their (non-methadone) opiate positive urine screens at baseline intake. This held true for both the intent-to-treat sample
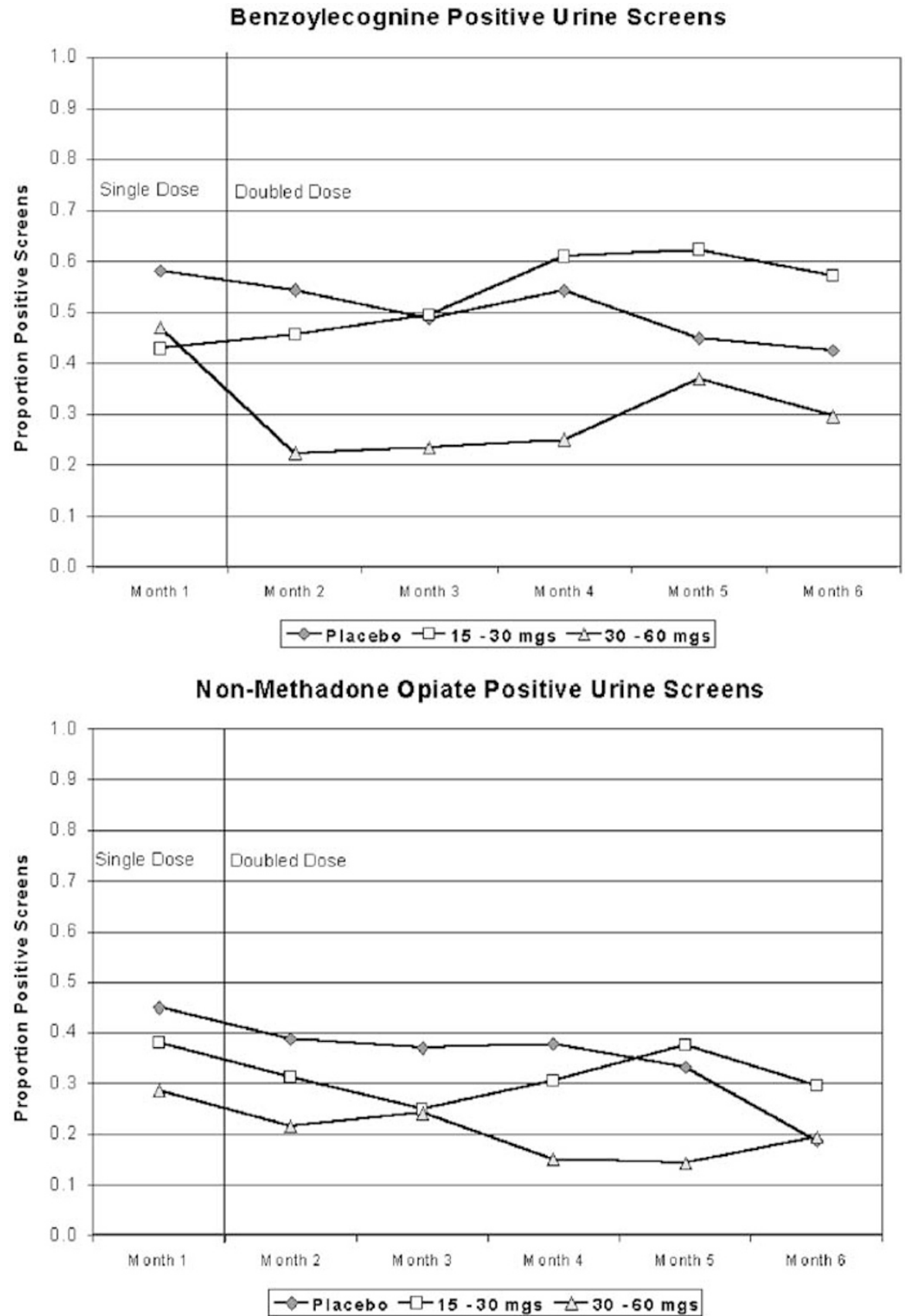

Figure 2 For the d-amphetamine + methadone study, dichotomous urine screen data (positive/negative) with a $300 \mathrm{ng} / \mathrm{ml}$ cutoff for BE (top) and opioids (bottom) from study intake to completion (the vertical line indicates d-amphetamine dose doubling). (a) BE-positive urine screens, (b) Opioid-positive urine screens. 
$(52.5,69.2$, and $67.9 \% ; p>0.28)$ as well as the evaluable sample $(60,69.6$, and $68.4 \% ; p>0.50)$, for the placebo, $15 /$ 30 , and $30 / 60 \mathrm{mg} \mathrm{d}$-amphetamine groups, respectively. Figure $2 \mathrm{~b}$ presents illicit opiate use across the time for $\mathrm{d}$ amphetamine single/doubled dosages for the three dose groups. The proportion of opiate-positive (non-methadone) urine screens decreased as a function of moving from single to doubled d-amphetamine doses in the active groups. This decrease was seen in each of the active dose groups $(\mathrm{F}=5.99, \mathrm{df}=1,55, p=0.018 ;$ effect-size $f=0.33)$. In addition, the $30 / 60 \mathrm{mg}$ group produced the lowest rate of opiate-positive urine screens, followed by the 15/30 and placebo groups. These differences among the three dose groups approached statistical significance $(\mathrm{F}=2.7, \mathrm{df}=2$, $57, p=0.07$; effect-size $f=0.31$ ). Illicit opiate use at intake was used as a covariate for the above analyses and, as with the findings with cocaine, was positively associated with later illicit opiate use $(\mathrm{F}=21.1, \mathrm{df}=1,57, p<0.001)$.

Blood pressure: Systolic and diastolic pressures and heart rate were recorded at intake and weekly thereafter. The aggregated data by study period (intake/dosing/dose doubling) were analyzed using intake measures as covariates. The mean systolic/diastolic pressures across intake, single, and doubled dose are presented in Table 2. Subjects were generally normo-tensive with no differences across groups at intake. Systolic blood pressures increased as a function of dose group $(\mathrm{F}=3.31, \mathrm{df}=2,65, p=0.043)$ and single $v s$ doubled dosages $(\mathrm{F}=2.05, \mathrm{df}=6,253 p=0.060)$. The pattern for diastolic pressure was similar but only differed as a function of single $v s$ doubled dosages $(\mathrm{F}=2.32$, $\mathrm{df}=6,262, p=0.034)$. The heart rate varied in a complex pattern in which the $30 / 60 \mathrm{mg}$ group was lowest at intake

Table 2 Systolic BP, Diastolic BP, and HR

\begin{tabular}{lllcc}
\hline Measure & Group & Intake & Single dose & Doubled dose \\
\hline Systolic & Placebo & 124.7 & 123.3 & 127.3 \\
& $15 / 30 \mathrm{mg}$ & 119 & 116.1 & 119.1 \\
& $30 / 60 \mathrm{mg}$ & $1 \mid 4.6$ & 120.2 & 124.4 \\
& & & & \\
Diastolic & Placebo & 77.8 & 77.4 & 80.4 \\
& I5/30 mg & 70.8 & 72.9 & 74.6 \\
& $30 / 60 \mathrm{mg}$ & 68.9 & 73.6 & 74.8 \\
& & & & 74 \\
Heart rate & Placebo & 74.4 & 75.2 & 79.6 \\
& I5/30 mg & 78.7 & 74.5 & 79.6 \\
\hline
\end{tabular}

but was higher and equal to that of the $15 / 30 \mathrm{mg}$ group during the doubled dose phase, while the placebo group's heart rate stayed moderate and steady across phases $(\mathrm{F}=1.83, \mathrm{df}=12,246, p=0.045)$.

Beck depression inventory: Grand Means (SD) for BDI scores at Intake, Phase 1, and Phase 6 were 16.7(10.3), 7.4(7.8), and 5.4(7.3), respectively. There were no differences in BDI scores at intake $(p=0.76, n=62)$. BDI scores collected at the end of the single and doubled dose phases were assessed for group or phase differences, using intake scores as a covariate. No significant changes were seen across dose groups ( $p>0.68, n=62)$. The slight decrease in scores observed as a function of single $v s$ doubled dose was different at the trend level $(\mathrm{F}=2.78, \mathrm{df}=1,51, p=0.10$, effect-size $f=0.234$ ).

HIV: Of the 94 subjects in the intent-to-treat group, three were HIV positive at intake. No subject converted from negative to positive during the study.

\section{Study II: Risperidone for Cocaine and Methadone for Opioid Dependence}

\section{Method.}

Subjects: Informed consent and intake procedures were performed as in Study I for 120 subjects. All subjects completing intake for study admission and medicating met inclusion criteria and were in generally good psychiatric and medical health.

Design: There was random assignment to either placebo or one of two risperidone doses in this double-blind trial. The study sequence included a 2-day intake period with a 2week medication stabilization period, a 24 -week medication trial, and a post-trial dose reduction period (Table 3 ).

Psychosocial therapy: Manual-driven cognitive behaviorally based psychosocial therapy was provided once weekly.

Medication: Risperidone was scheduled for administration late in the day to minimize problems with daytime sedation. Medication and placebo capsules were identical in appearance. Placebo and risperidone were packed in capsules with riboflavin to monitor compliance. The total daily dose of riboflavin was $100 \mathrm{mg}$. In this study, the single daily dose capsules were in blister packs for the intervening 'take-home' days. The doses were 2 or $4 \mathrm{mg}$ per day. Methadone was administered and dose reduction at study end proceeded as in Study I. Subjects were required to return the blister packs as they had the MEMS bottles in Study I.

Table 3 Design, Study II

\begin{tabular}{|c|c|c|c|c|}
\hline Phases & Intake & Stabilization & Study phase & Study end \\
\hline Duration & 2 days & 10 days & 168 days & $7-10$ days risp 60 days methadone \\
\hline \multicolumn{5}{|l|}{ Groups } \\
\hline Placebo+methadone & No drug & Placebo+1.I mg/kg & Placebo+1.I mg/kg & Dose reductions \\
\hline Risperidone+methadone & No drug & $2 \mathrm{mg}+1.1 \mathrm{mg} / \mathrm{kg}$ & $2 \mathrm{mg}+1.1 \mathrm{mg} / \mathrm{kg}$ & Dose reductions \\
\hline Risperidone+methadone & No drug & $4 \mathrm{mg}+1.1 \mathrm{mg} / \mathrm{kg}$ & $4 \mathrm{mg}+1.1 \mathrm{mg} / \mathrm{kg}$ & Dose reductions \\
\hline
\end{tabular}


Measures and data analysis: Measures administered at intake and during the study were the same as those in Study I as was data analysis.

\section{Results}

Subjects: A total of 120 subjects signed consent forms to participate. None offered participation refused. Of these subjects, 96 completed evaluation and were randomized to placebo $(N=33), 2 \mathrm{mg}(N=32)$, or $4 \mathrm{mg}(N=31)$ risperidone (intent-to-treat sample) In all, 21 subjects dropped or transferred during intake evaluation and 11 subjects did not complete the medication run-up phase. In total, 64 subjects began the 24-week study phase (evaluable sample); 36 completed all study requirements, remaining the full duration of the clinical trial. The mean baseline methadone dose for subjects in the three groups was $70 \mathrm{mg}$ based on the $1.1 \mathrm{mg} / \mathrm{kg}$ dosing strategy.

Sample characteristics: The intent-to-treat sample $(N=96)$ was $40.6 \%$ female, $10.4 \%$ black, $79.2 \%$ white, and $10.4 \%$ Hispanic. In total, $25 \%$ were employed full or part time, $68 \%$ were unemployed and the remainder were retired or students. The mean age was $36.9(\mathrm{SD}, 7.5)$ years, with a mean educational level of 12.3 (SD, 2.4) years. There were no significant group differences in these demographic variables. Subjects reported using crack or freebase $(39.6 \%)$, powder $(42.7 \%)$, or 'speed balls' $(17.7 \%)$. This distribution did vary by dose group with relatively more subjects reporting speedball use (at intake) in the placebo group compared to the two active treatment groups (LR $\left.\chi^{2}=10.1, \mathrm{df}=4, p=0.04, n=96\right)$. The frequency of cocaine use reported at intake was 'less than once/week,' $20.9 \%$, 'once/week,' 6.3\%, 'several times/week,' 38.5\%, 'once/day,' $28.1 \%$, and 'greater than three times/day,' $6.3 \%$, with no significant differences among subjects assigned to dose groups $(p>0.50)$. Examination of demographics and subject characteristics for the evaluable subset of subjects revealed patterns nearly identical to those of the larger group and no differences on the variables were found by treatment group assignment.

Retention: Based on the 96 subjects in the intent-to-treat sample, the study completion rates for placebo, 2, and $4 \mathrm{mg}$ groups were $21.2,34.4$, and $45.2 \%$, respectively. The difference among groups was not significant ( $\operatorname{LR} \chi^{2}=4.24$, $\mathrm{df}=2, p=0.120, N=96)$. Retention curves for the three groups are presented in Figure 3. Survival analysis of three group's retention curves did not reveal any reliable differences (LR $\chi^{2}=3.68 \mathrm{df}=2, p=0.159, N=96$ ). The study completion rates for the evaluable sample were: 35.0 , 50.0 , and $63.6 \%$ for placebo, 2, and $4 \mathrm{mg}$ groups, respectively. Retention curves for patients who successfully entered the 'study' phase showed a pattern similar to the intent-to-treat pattern. Once again, the three groups, taken together, did not differ in terms of their retention curves $\left(\mathrm{LR} \chi^{2}=2.85, \mathrm{df}=2, p=0.241, N=64\right)$.

Compliance: Compliance measured by riboflavin fluorescence (cutoff $<10$ ) was $88.9,86.4$, and $87.4 \%$ for the 0,2 , and $4 \mathrm{mg}$ dose groups, respectively.

Dropouts and side effects: At the $4 \mathrm{mg}$ dose, drowsiness, sedation, and fatigue were verbally reported. Three patients verbally reported similar side effects as reasons for withdrawing despite being in the placebo group. Examining the individual medication effect items indicated no differences due to drug dose. There were differences across time (weeks 1-8, 9-16, and 17-24) after baseline was covaried. In each case, the trend was for a decrease in reporting of the effect over time. The effects were as follows: eating differently $(\mathrm{F}=5.23, \mathrm{df}=42,43, p=0.009)$; happier $(\mathrm{F}=10.9, \mathrm{df}=2,45$, $p=<0.0001)$; coughing/breathing problems $(\mathrm{F}=6.35$, $\mathrm{df}=2,50, \quad p=0.003) ; \quad$ constipated $\quad(\mathrm{F}=14.2, \quad \mathrm{df}=2,50$, $p=0.0001)$; nausea $(\mathrm{F}=4.94, \mathrm{df}=2,50, p=0.011)$; vomited $(\mathrm{F}=3.58, \mathrm{df}=2,47, \quad p=0.036) ;$ more energy $(\mathrm{F}=3.45$, $\mathrm{df}=2,53, p=<0.039)$; less energy $(\mathrm{F}=5.45, \mathrm{df}=2,45$, $p=0.008)$; felt high $(\mathrm{F}=7.50, \mathrm{df}=2,33, p=0.002)$; heart

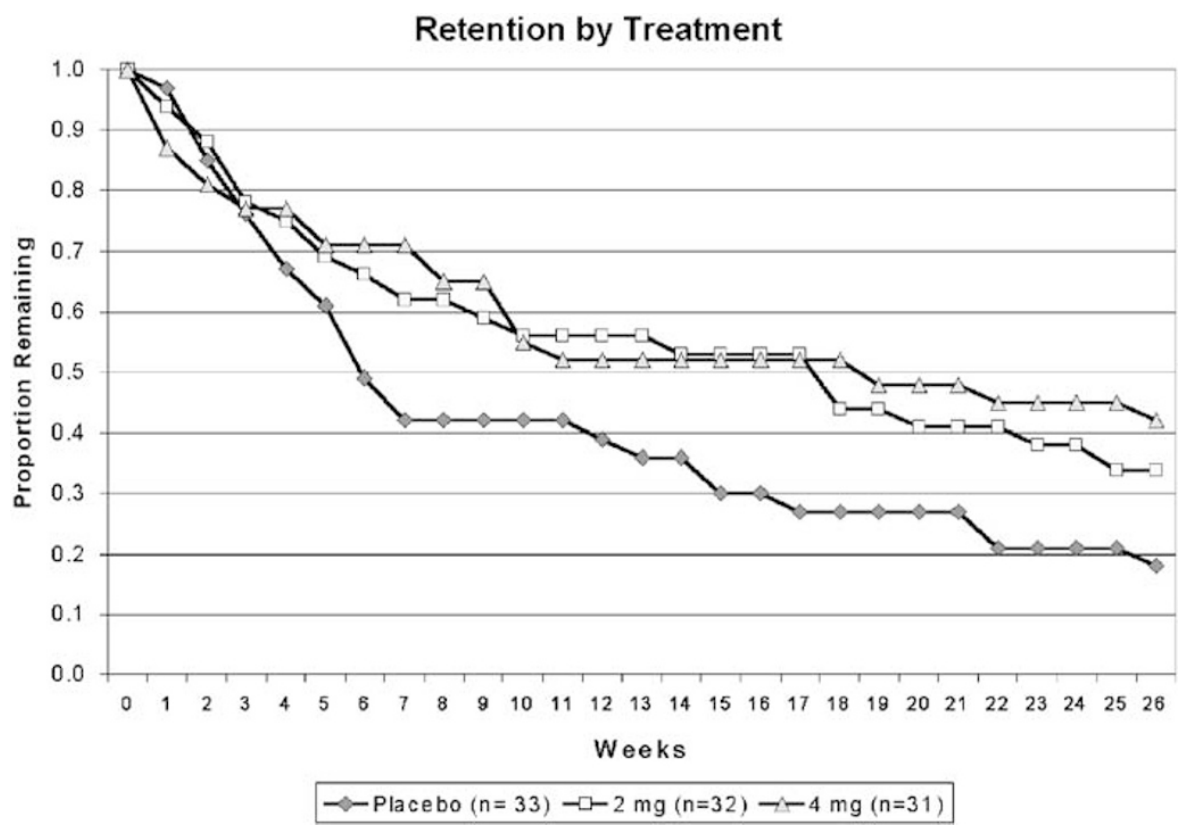

Figure 3 Retention for two active risperidone + methadone and placebo + methadone groups. 
beating slower $(\mathrm{F}=3.57, \mathrm{df}=2,52, p=0.035)$; mouth/ tongue twitch $(\mathrm{F}=3.52, \mathrm{df}=2,43, p=0.038)$; muscles twitch $(\mathrm{F}=3.53, \mathrm{df}=2,41, p=0.039) ;$ drowsy $(\mathrm{F}=14.68, \mathrm{df}=2,53$, $p<0.001)$; dizzy $(\mathrm{F}=4.59, \mathrm{df}=2,45, p=0.015)$; and sleeping better $(\mathrm{F}=6.38, \mathrm{df}=2,53, p=0.003)$.

Cocaine use: Analysis of the proportion of urine screens positive for cocaine revealed no main effect differences across the three drug groups $(\mathrm{F}=0.09, \mathrm{df}=2,65, p>0.9)$. A main effect of time was present, with more cocaine-positive urine samples at the beginning and end of the trial period (across dose $)(\mathrm{F}=2.61, \mathrm{df}=5,189, p=0.026$; effect-size $f=0.263)$. Additionally, a dose by time interaction was found $(\mathrm{F}=1.93, \mathrm{df}=10,189, p=0.043$; effect-size $f=0.32)$; however, as seen in Figure $4 \mathrm{a}$, no clear interpretation of this statistical effect can be made.

Separate analyses to determine whether quantitative BE urine screen values might reveal differences in outcome among the dose groups produced results similar to those for the dichotomous measure, indicating that the simple dichotomous dimension of positive/negative presented in Figure $4 \mathrm{a}$ accurately portrays the urine screen results. The quantitative intake values were also highly predictive

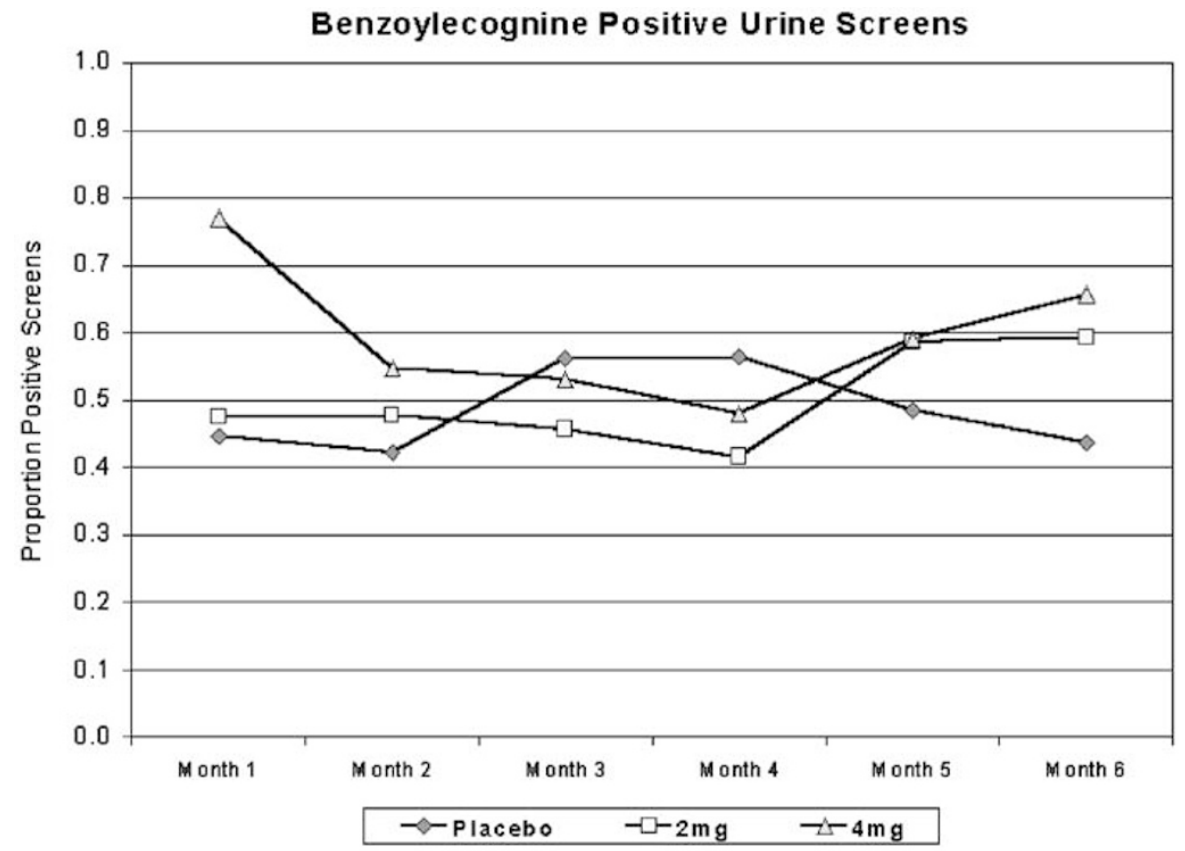

Non-Methadone Opiate Positive Urine Screens

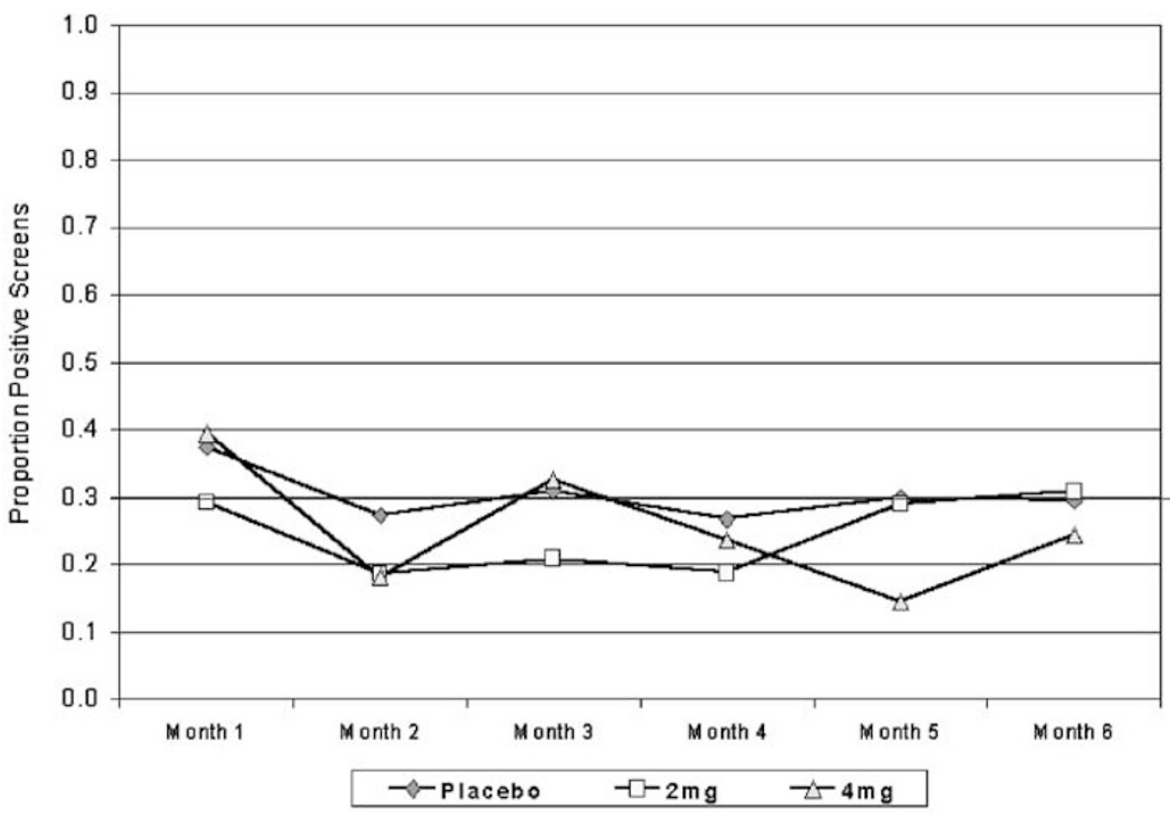

Figure 4 For therisperidone + methadone study, dichotomous urine screen data (positive/negative) with a $300 \mathrm{ng} / \mathrm{ml}$ cutoff for BE (top) and opioids (bottom) from study intake to completion. (a) BE-positive urine screens, (b) opioid-positive urine screens. 
of subsequent use measured quantitatively (all $p$-values $<0.001)$.

Illicit opioid use: Urine screen values were analyzed for opiate use (Figure $4 \mathrm{~b}$ ). Reliable differences were not seen when data were analyzed by dose level $(p>0.9)$, nor was there a dose by month interaction $(p>0.37)$. There was a shallow U-shaped trend in the monthly opiate use data (averaged across dose groups) that approached but did not reach statistical significance $(\mathrm{F}=2.13, \mathrm{df}=5,180, p=0.064$; effect-size $f=0.253$ ). As usual, intake opiate screens, used as a covariate, were highly correlated with the outcome $(\mathrm{F}=6.06, \mathrm{df}=1,58, p=0.017)$.

Blood pressure: Subjects were generally normo-tensive with no differences across groups at intake. The mean systolic/diastolic pressures (standard error) across Intake, stabilization, and treatment months for placebo are presented in Table 2. Analysis of systolic pressures indicated that groups differed by dose $(\mathrm{F}=4.0, \mathrm{df}=2,71$, $p=0.022$ ), with the placebo group registering systolic pressures greater than either active dose group. This pattern was consistent across all time periods, that is, there was no effect of time $(p>0.12)$ nor was there any indication of a dose by time interaction $(p>0.14)$. Diastolic pressures were lower in the $4 \mathrm{mg}$ group $(\mathrm{F}=3.16, \mathrm{df}=2,69, p=0.049)$. No changes over time were observed $(p>0.12)$ and the pattern was the same for all groups across time $(p>0.56)$. Heart rate values evidenced no difference by dose, time, or dose across time $(p>0.37)$.

Beck depression inventory: Grand Means (SD) for BDI scores at Intake, Month 1, and Month 6 were $17.8(9.2), 8.16(9.2)$, and 4.56(7.5), respectively. A covariate-adjusted (Intake BDI scores) analysis of BDI scores indicated a decline over the course of the 24-week trial $(\mathrm{F}=2.84, \mathrm{df}=23,913, p<0.001)$; however, scores were not different as a function of dose group $(p>0.24)$, nor was there any evidence of a dose group by time interaction $(p>0.74)$

$H I V$ : Of the 75 subjects who began dose run-up, four were HIV positive, and two were indeterminate, at intake and follow-up screening. No one converted from negative to positive during the study.

\section{DISCUSSION}

Two studies conducted in parallel were identical in major features, with the exception of the medication examined for treatment of cocaine dependence. There was no benefit from risperidone and a modest but significant reduction in cocaine use in subjects receiving $60 \mathrm{mg}$ d-amphetamine in a sustained release preparation. A third finding of some importance concerned retention in relation to methadone administration.

While power is necessarily decreased as patients drop out, both studies had observed power sufficient to detect treatment effects in the 'medium' size range $(f=0.25$ as defined by Cohen, 1988), and in both studies such treatment effects were found. The use of Maximum Likelihood-based analyses, where all observations are used, provides an analysis more sensitive to treatment effects than analyses where patients are 'list-wise' deleted from the data set if any observation is missing.
Discussion of the d-amphetamine regimen is warranted. Early in our work with d-amphetamine, some experts expressed concern about safety and efficacy. Safety concerns produced the two-phase design. A cardiologist (author AD) was involved in all subject enrollment and continuation decisions. This, no doubt, contributed to the absence of any adverse events. d-Amphetamine had a modest effect on BP and HR in these carefully screened subjects. Differences that emerged between placebo and the active doses may have been due to group baseline differences (lower for the 30/60 d-amphetamine group). The data suggest that a continuous single run-up period would suffice.

Our first randomized double-blind study of d-amphetamine as a prototype agonist-like drug for stimulant dependence treatment (Grabowski et al, 2001) pointed to improved retention and reduction in BE-positive screens. A divergent response for retention $v s$ cocaine use reductions at different doses paralleled other agonist literature; for example, the utility of methadone varies as a function of dose (Rhoades et al, 1998; Strain et al, 1999), clinical circumstances of its administration (Ball and Corty, 1988), and other environmental factors (Rhoades et al, 1998). Variability should also be expected in the stimulant substitution case. Here, unlike the single diagnosis report, there was no separation of the retention and diminished cocaine use. The longer duration of this study may have contributed to the more congruent result.

Compliance with the medication regimen in this study was somewhat less than in the previous d-amphetamine study as measured by MEMS, riboflavin, and amphetamine metabolites in urine. The cause of the discrepancy between urine riboflavin and amphetamine measures is unknown. Some individuals may metabolize amphetamine more effectively and even the sustained release preparation half-life of less than $8 \mathrm{~h}$ might produce negative screens. 'Self-adjustment' of doses may have occurred despite compliance-monitoring measures. However, the overall riboflavin results of 77,78 , and $80 \%$, respectively, for the placebo, $15 / 30 \mathrm{mg}$, and $30 / 60 \mathrm{mg}$ doses indicate very respectable compliance (eg see Velasquez et al, 2003). We suggest that the riboflavin measures more accurately represent compliance. The $<3 \%$ rate of amphetamine use in the placebo group was accounted for by two individuals near study end. Most important is that the data are important to evaluate a study and provide direction for future work.

Discussion of the methadone regimen is likewise warranted. Methadone at $1.1 \mathrm{mg} / \mathrm{kg}$ is roughly comparable, though slightly lower than the upper dose used in our earlier research (Rhoades et al, 1998) and by others (Strain et al, 1999) in single diagnosis subjects. Retention was about the same or better than that reported for a large methadone treatment clinic for the 'high dose' ( $>100 \mathrm{mg}$ ) in long-term well-stabilized patients (Maxwell and Shinderman, 2002). The populations are not directly comparable since ours were diagnosed dual dependence, were newly introduced to methadone and risperidone/d-amphetamine at study start, and participated in a clinic devoted solely to research. However, methadone in the baseline dosage range used previously in our clinic does not sustain retention as well in the dually dependent subject. 
The actual dose range based on $1.1 \mathrm{mg} / \mathrm{kg}$ was due in part to earlier criticism of our preference to use 'high' $(100 \mathrm{mg})$ in opioid dependence studies. The $\mathrm{mg} / \mathrm{kg}$ strategy seemed preferable to any fixed dose procedure. The mean doses $(70 \mathrm{mg})$ for the groups in these studies approximated those accepted as intermediate for the time. Some conservatism was dictated by concerns about individual differences in tolerability of d-amphetamine or risperidone in combination with methadone. We also wished to avoid methadone doses that might obscure effects of d-amphetamine or risperidone. Future studies should use a higher $\mathrm{mg} /$ $\mathrm{kg}$ methadone dose. Related to dosing and design were findings on the influence of clinic visit frequency on retention. In two earlier studies conducted in parallel (cocaine dependence, Grabowski et al, 1995; opioid dependence, Rhoades et al, 1998), it was clearly demonstrated that better retention resulted from fewer visits per week. Thus, here we used the two visit per week procedure, albeit with the lessened opportunity for observation. Subsequently, NIDA enunciated a preference for thriceweekly visits in cocaine dependence studies to provide better urine screen coverage. More recently, the higher visit frequency requirement has been diminished in stature given increased reliance by NIDA on combining use of self-report with urine sample results.

The continuity of designs provided a quartet of comparable studies for later analysis as well as the ability to compare data to the earlier work. The two dual dependence studies were initiated shortly after beginning two previously reported parallel 12-week single diagnosis trials. Comparable conditions existed across the four studies with respect to clinic, community, and drug supply variables. Across all four studies, retention from worst to best was cocaine dependent/receiving risperidone (Grabowski et al, 2000a), cocaine dependent/receiving d-amphetamine (Grabowski et al, 2000b, 2001), dual dependence/receiving risperidone + methadone, and dual dependence/receiving $\mathrm{d}$-amphetamine + methadone. Cocaine use across active medication conditions in the four studies from highest to lowest was risperidone alone, risperidone + methadone, $d$ amphetamine alone, and d-amphetamine + methadone (Table 4).

\section{Abuse of and Treatment With the Opioid-Stimulant Agonist-like Combination}

Concurrent use of heroin and cocaine is common. Treatment of heroin use with methadone alone produces equivocal results on cocaine use (eg Strain et al, 1999; Rhoades et al, 1998; Grabowski et al, 1993; Oliveto et al, 1993; Stine et al, 1991). While dual dependence presents a dilemma in treatment, the comparative data presented here suggest that retention is less problematic than in single diagnosis cocaine subjects.

The rationale for the use of agonist-like d-amphetamine is clear. Parallels to cocaine in behavioral action permit an assumption of partial 'substitution', but as with methadone for heroin, with a therapeutically attractive profile. The actions of amphetamines have been well understood for decades (Goodman and Gilman, 1941; Laties and Weiss, 1981, 1967; Weiss and Laties, 1970, 1962) and though recently in disfavor, they have a reasonable risk-benefit ratio. Similarly, stimulant/mu-opioid combinations have been well described in the preclinical literature (Lamas et al, 1998; Negus et al, 1998; Mello and Negus, 2001; Negus, 2003; Negus and Mello, 2003a,b). Even under well-controlled preclinical laboratory, and clinical laboratory settings (Foltin and Fischman, 1992, 1996, 1998), substantial 'individual differences' emerge and this is observed in clinical settings. Some data emerge from pain treatment where the opioid and stimulant combination is used effectively (Forrest et al, 1977; Bourke et al, 1983; McManus and Panzarella, 1986; Payne, 1997 personal communication). Still, in a human laboratory study with concurrent IM morphine and $\mathrm{d}$-amphetamine administration to nondependent individuals, Jasinski and Preston (1986) observed greater euphoria and mutual antagonism of side effects. They suggested increased abuse liability of the combination. We found no evidence of undue or excessive response to the methadone $+\mathrm{d}$-amphetamine combination as determined by regular interviews and self-report measures in these cocaine + heroin-dependent subjects. Thus, concurrent administration of methadone and amphetamine proves plausible for treatment of cocaine + opioid dependence. Particularly interesting was the trend toward lower

Table 4 Comparison, Retention in Four Studies

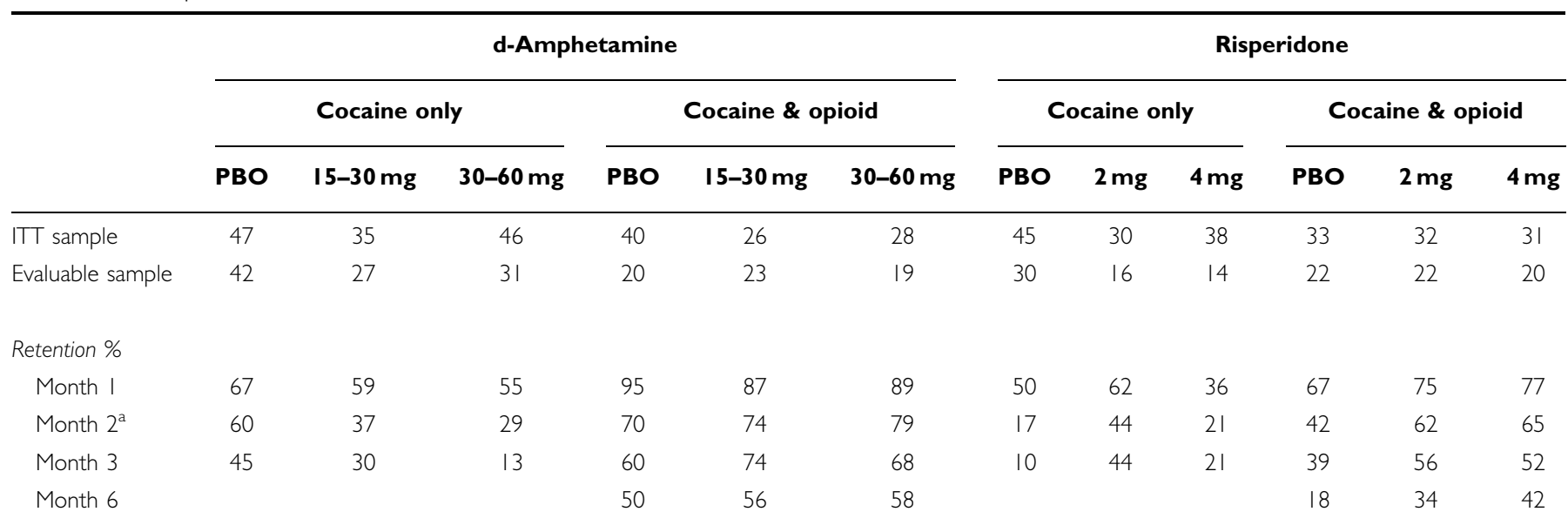

Doses doubled to 30 or $60 \mathrm{mg}$ in the d-amphetamine studies. 
opioid use during the period of $60 \mathrm{mg} \mathrm{d}$-amphetamine + methadone combination.

Given the relative independence of the two medications within clinical dose ranges, arriving at optimal individual treatment might be simplified in traditional clinical settings. Our combined results suggest that the optimal dose with the sustained release preparation may be $>60 \mathrm{mg}$ for chronic cocaine users. Confirmation of potential effectiveness of stimulant 'substitution' can be found in descriptive and randomized trials (Charnaud and Griffiths, 1998; Shearer et al, 2001) in which d-amphetamine immediate release was administered to amphetamine-abusing patients. Shearer et al (2002) have made a logical argument for substitution therapy in stimulant dependence. However, Shearer et al (2003) reporting on immediate release amphetamine for cocaine dependence produced positive trends but not significant placebo-medication differences. The success of the agonist model may be dependent on sustained release preparations Grabowski et al (2000b, 2001).

\section{Treatment with Opioid-Stimulant Antagonist-Like Combination}

The most commonly available antagonist-like medications are antipsychotics. Patients entering treatment for cocaine dependence may be taking antipsychotic agents, but abuse of this combination is unreported. Initiating and maintaining subjects on methadone and risperidone could produce adverse effects (eg Wines and Weiss, 1999). However, no substantial side effects were observed beyond those reported in Grabowski et al (2000a) and no additive effects were apparent. The better retention in the $4 \mathrm{mg}$ risperidone + methadone group compared to placebo suggests a favorable interaction of unknown cause, but was not accompanied by reductions in cocaine use. There was, in the risperidone + methadone compared to the d-amphetamine + methadone trial, an unmeasured, perhaps unmeasurable difference, which might contribute to lessened retention. There were necessarily differences in the consent forms and weekly queries about side effects for the two medications. Those for $\mathrm{d}$-amphetamine may have been better understood and accepted than those of risperidone by cocaine-dependent subjects.

An abundant and complex preclinical literature exists describing actions of dopamine antagonists, including reported reductions in cocaine self-administration (eg Rasmussen et al, 2000) and modulation of behavioral biological effects of cocaine (Van Campenhout et al, 1999; Manzanedo et al, 2001). Still, the current literature suggests that there is little reason to proceed with this medication. However, plausible alternatives for cocaine dependence may emerge. Some preclinical and clinical data suggest that olanzapine might be efficacious for administration in cocaine dependence (Meil and Schecter, 1997; Bano et al, 2001; Howell and Wilcox, 2002).

\section{Conclusions}

Having completed these studies without adverse events, we suggest that higher methadone and d-amphetamine doses might be feasible and convey advantage, and this work is proceeding. In standard clinics, dose could be adjusted directly based on drug screen results, a feature that was not possible in the context of this study design. It is clear that the methadone $+\mathrm{d}$-amphetamine combination used here was significantly better than methadone + placebo in either study, or methadone + risperdione for concurrent cocaine and opioid dependence. While the results may be termed 'modest', the results for d-amphetamine are better than those for any other rigorously examined medication for the serious problem of cocaine dependence and abuse. Finally, data for an agonist strategy to the treatment of psychostimulant dependence are accumulating, and suggest the validity of pursuing the agonist model for treatment of stimulant dependence.

\section{ACKNOWLEDGEMENTS}

Contributions of staff members of the SARC Treatment Research Clinic are gratefully acknowledged. RA Meisch MD PhD and SS Negus PhD (Harvard) provided thoughtful and valuable editorial comment. Reese Jones MD (UCSF) was instrumental in the development of d-amphetamine projects and provided much appreciated ongoing consultation. No conflicts of interest existed for any author. The work was supported by NIDA Grants DA P50-9262, DA RO1-6143, and DA RO1 16302.

\section{REFERENCES}

Ball JC, Corty E (1988). Basic issues pertaining to the effectiveness of methadone maintenance treatment. NIDA Res Monogr 86: 178-191.

Bano MD, Mico JA, Aguietas M, Lopez ML, Guillen JL (2001). Olanzapine efficacy in the treatment of cocaine abuse in methadone maintenance patients. Interactions and plasma levels (abstract English). Actas Esp Psiquiatria 29: 215-220.

Beck AT, Steer RA, Brown GK (1996). Beck Depression Inventory, 2nd edn. The Psychological Corporation: San Antonio, TX.

Bourke DL, Allen PD, Rosenberg M, Mendes RW, Karabelas AN (1983). Dextroamphetamine with morphine: respiratory effects. J Clin Pharmacol 23: 65-70.

Charnaud B, Griffiths V (1998). Levels of intravenous drug misuse among clients prescribed oral dexamphetamine or oral methadone: a comparison. Drug Alcohol Depend 52: 79-84.

Cohen J (1988). Statistical Power Analysis for the Behavioral Sciences, 2nd edn Lawrence Erlbaum Associates: Hillsdale, NJ.

First M, Spitzer R, Gibbon M, Williams J (1995). Structured Clinical Interview for DSM-IV Axis I Disorders-Patient Edition. New York State Psychiatric Institute: New York.

Foltin RW, Fischman MW (1992). The cardiovascular and subjective effects of intravenous cocaine and morphine combinations in humans. J Pharmacol Exp Therapeut 261: 623-632.

Foltin RW, Fischman MW (1996). Effects of methadone or buprenorphine maintenance on the subjective and reinforcing effects of intravenous cocaine in humans. J Pharmacol Exp Therapeut 278: 1153-1164.

Foltin RW, Fischman MW (1998). Effects of 'binge' use of intravenous cocaine in methadone-maintained individuals. Addiction 93: 825-836.

Forrest Jr WH, Brown Jr BW, Brown CR, Defalque R, Gold M, Gordon HE et al (1977). Dextroamphetamine with morphine for the treatment of postoperative pain. $N$ Engl J Med 296: 712-715.

Goodman L, Gilman A (1941). The Pharmacological Basis of Therapeutics. The Macmillan Co.: NY.

Grabowski J, O'Brien CP, Greenstein R, Ternes J, Long M, Steinberg-Donato S (1979). Effects of contingent payment on 
compliance with a naltrexone regimen. Am J Drug Alcohol Abuse 6: $355-365$

Grabowski J, Rhoades H, Elk R, Schmitz J, Creson D (1993). Methadone dosage, cocaine and opiate abuse [letter]. Am J Psychiatry 150: 675.

Grabowski J, Rhoades H, Elk R, Schmitz J, Davis C, Creson D et al (1995). Fluoxetine is ineffective for treatment of cocaine dependence or concurrent opiate and cocaine dependence: two placebo-controlled double-blind trials. J Clin Psychopharmacol 15: $163-174$.

Grabowski J, Rhoades H, Schmitz J, Stotts A, Daruzska LA, Creson $\mathrm{D}$ et al (2001). Dextroamphetamine for cocaine-dependence treatment: a double-blind randomized clinical trial. J Clin Psychopharmacol 21: 522-526; (Also summarized and reviewed in Evidence Based Medicine: Mental Health, 2002).

Grabowski J, Rhoades H, Silverman P, Schmitz JM, Stotts A, Creson D et al (2000a). Risperidone for the treatment of cocaine dependence: randomized, double-blind trial. J Clin Psychopharmacol 20: 305-310.

Grabowski J, Rhoades H, Stotts A, Schmitz J, Creson D, Moeller G et al (2000b). D-amphetamine for treatment of cocaine dependence: randomized double blind placebo controlled trials. Drug Alcohol Depend (Abstracts CPDD) 60: 216.

Greenstein RA, O'Brien CP, McLellan AT, Woody GE, Grabowski J, Long $\mathrm{M}$ et al (1981). Naltrexone: a short-term treatment for opiate dependence. Am J Drug Alcohol Abuse 8: 291-300.

Griffiths RR, Brady JV, Bigelow GE (1981). Predicting the dependence liability of stimulant drugs. NIDA Res Monog 37: 182-196; (Washington DC. DHHS (ADM) 81-1137).

Gutierrez-Esteinou R, Grebb JA (1997). Risperidone: an analysis of the first three years in general use. Int Clin Psychopharmacol 12(Suppl 4): s3-s10.

Jasinski DR, Preston KL (1986). Evaluation of mixtures of morphine and d-amphetamine for subjective and physiological effects. Drug Alcohol Depend 17: 1-13.

Howell LL, Wilcox KM (2002). Functional imaging and neurochemical correlates of stimulant self-administration in primates. Psychopharmacology 163: 352-361.

Katz EC, Chutuape MA, Jones HE, Stitzer ML (2002). Voucher reinforcement for heroin and cocaine abstinence in an outpatient drug-free program. Exp Clin Psychopharmacol 10: 136-143.

Klee H, Wright S, Carnwath T, Merrill J (2001). The role of substitute therapy in the treatment of problem amphetamine use. Drug Alcohol Rev 20: 417-429.

Lamas X, Negus SS, Gatch MB, Mello NK (1998). Effects of heroin/ cocaine combinations in rats trained to discriminate heroin or cocaine from saline. Pharmacol Biochem Behav 60: 357-364.

Laties VG, Weiss B (1967). Performance enhancement by the amphetamines: a new appraisal. In: Brill $\mathrm{H}$ et al (eds) NeuroPsycho-Pharmacology. Excerpta Medica Foundation: Amsterdam. pp 800-808.

Laties VG, Weiss B (1981). The amphetamine margin in sports. Fed Proc 40: 2689-2692.

Leri F, Bruneau J, Stewart J (2003). Understanding polydrug use: review of heroin and cocaine co-use. Addiction 98: 7-22.

Levin FR, McDowell D, Evans SM, Brooks D, Spano C, Nunes EV (1999). Pergolide mesylate for cocaine abuse: a controlled preliminary trial. Am J Addict 8: 120-127.

Manzanedo C, Aguilar MA, Rodriguez-Arias M, Minarro J (2001). Effects of dopamine antagonists with different receptor blockade profiles on morphine-induced place preference in male mice. Behav Brain Res 121: 189-197.

Maxwell S, Shinderman MS (2002). Optimizing long term response to methadone maintenance treatment: a 152-week Follow-up using higher dose methadone. J Addict Dis 21: 1-12.

McLellan AT, Kusher H, Metzger D, Peters R, Smith I, Grisson G et al (1992). The fifth edition of the Addiction Severity Index. J Substance Abuse Treat 8: 199-213.
McManus MJ, Panzarella C (1986). The use of dextroamphetamine to counteract sedation for patients on a morphine drip. J Assoc Pediatr Oncol Nurses 3: 28-29.

Meil WM, Schecter MD (1997). Olanzapine attenuates the reinforcing effects of cocaine. Eur J Pharmacol 340: 17-26.

Mello NK, Negus SS (1996). Preclinical evaluation of pharmacotherapies for treatment of cocaine and opioid abuse using drug self-administration procedures. Neuropsychopharmacology 14: $375-424$.

Mello NK, Negus SS (2001). Effects of indatraline and buprenorphine on self-administration of speedball combinations of cocaine and heroin by rhesus monkeys. Neuropsychopharmacology 25: 104-117.

Negus SS (2003). Rapid assessment of choice between cocaine and food in rhesus monkeys: effects of environmental manipulations and treatment with d-amphetamine and flupenthixol. Neuropsychopharmacology 28: 919-931.

Negus SS, Gatch MB, Mello NK (1998). Discriminative stimulus effects of a cocaine/heroin 'speedball' combination in Rhesus monkeys. J Pharmacol Exp Therapeut 285: 1123-1136.

Negus SS, Mello NK (2003a). Effects of chronic d-amphetamine treatment on cocaine- and food-maintained responding under a progressive-ratio schedule in rhesus monkeys. Psychopharmacology 167: 324-332.

Negus SS, Mello NK (2003b). Effects of chronic d-amphetamine treatment on cocaine- and food-maintained responding under a second-order schedule in rhesus monkeys. Drug Alcohol Depend 70: $39-52$.

Newton TF, Ling W, Kalechstein AD, Uslaner J, Tervo K (2001). Risperidone pre-treatment reduces the euphoric effects of experimentally administered cocaine. Psychiatry Res 102: 227-233.

Oliveto A, Kosten T, Schottenfeld R, Ziedonis D (1993). Cocaine abuse among methadone-maintained patients. Am J Psychiatry 150: 1755.

Platt DM, Rowlett JK, Spealman RD (2002). Behavioral effects of cocaine and dopaminergic strategies for preclinical medication development. Psychopharmacology 163: 265-282.

Preston KL, Silverman K, Umbricht A, DeJesus A, Montoya ID, Schuster CR (1999). Improvement in naltrexone treatment compliance with contingency management. Drug Alcohol Depend 54: 127-135.

Rasmussen T, Sauerberg P, Nielsen EB, Swedberg MDB, Thomsen C, Sheardown MJ et al (2000). Muscarinic receptor agonists decrease cocaine self-administration rates in drug naïve mice. Eur J Pharmacol 402: 241-246.

Rhoades HM, Creson D, Elk R, Schmitz JM, Grabowski J (1998). Retention, HIV risk, and illicit drug use during treatment: methadone dose and visit frequency. Am J Public Health 88: 34-39.

Rothman RB, Blough BE, Baumann MH (2002). Appetite suppressants as agonist substitution therapies for stimulant dependence. Ann NY Acad Sci 965: 109-126.

Roy A, Roy M, Smelson DA (1998). Risperidone, ERG and cocaine craving [letter]. Am J Addict 7: 90.

Shearer J, Sherman J, Wodak A, Van Beek I (2002). Substitution therapy for amphetamine users. Drug Alcohol Rev 21: 179-185.

Shearer J, Wodak A, van Beek I, Mattick RP, Lewis J (2003). Pilot randomized double blind placebo-controlled study of dexamphetamine for cocaine dependence. Addiction 98: 1137-1141.

Shearer J, Wodak A, Mattick RP, van Beek I, Lewis J, Hall W et al (1999). A randomised controlled trial of feasibility of monitoring controlled prescribing of dexamphetamine. NDARC Technical Report, National Drug and Alcohol Research Centre, University of New South Wales, pp 1-43.

Shearer J, Wodak A, Mattick RP, Van Beek I, Lewis J, Hall W et al (2001). Pilot randomized controlled study of dexamphetamine substitution for amphetamine dependence. Addiction 96: 1289-1296. 
Stine SM, Burns B, Kosten T (1991). Methadone dose for cocaine abuse. Am J Psychiatry 148: 1268.

Strain EC, Bigelow GE, Liebson IA, Stitzer ML (1999). Moderate- $v s$ high-dose methadone in the treatment of opioid dependence: a randomized trial [see comments]. J Am Med Assoc 281: 1000-1005.

Van Campenhout N, De Haes P, Meert TF (1999). Inability of antipsychotics to antagonize the cueing properties of cocaine in rats. Pharmacol Biochem Behav 64: 435-438.

Velasquez MM, Wright K, Ingersoll KS (2003). Treatment adherence and cardiovascular disease. In: Fowler G (ed). Twenty Common Problems in Cardiology. McGraw-Hill: New York.

Villano CL, Rosenblum A, Magura S, Fong C (2002). Improving treatment engagement and outcomes for cocaine- using methadone patients. Am J Drug Alcohol Abuse 28: 213-230.

Wachtel SR, Ortengren A, de Wit H (2002). The effects of acute haloperidol or risperidone on subjective responses to methamphetamine in healthy volunteers. Drug Alcohol Depend 68: 23-33.

Weiss B, Laties VG (1962). Enhancement of human performance by caffeine and the amphetamines. Pharmacol Rev 14: 1-36.

Weiss B, Laties VG (1970). Reconciling the effects of amphetamine on human and animal behavior. In: de C Baker SB (ed). The Correlation of Adverse Effects in Man with Observations in Animals. Excerpta Medica Foundation: Amsterdam. pp 32-36.

Wines JD, Weiss RD (1999). Opioid withdrawal during risperidone treatment. J Clin Psychopharmacol 19: 265-266. 